\title{
THE EFFECT OF COMPUTER MEDIATED CONFERENCING AND COMPUTER ASSISTED INSTRUCTION ON STUDENT LEARNING OUTCOMES
}

\author{
Darrell L. Cain, Ph.D. \\ Atlanta Technical College
}

Paul E. Pitre, Ph.D.

Washington State University

\begin{abstract}
The trend toward increased technology in traditional higher education classrooms has been met with both optimism and criticism. One of the major criticisms of technology in the college classroom is that it does little, if anything, to improve student learning. Taking this view of technology into account, this study examined how the use of technology contributed to student learning outcomes after controlling for key student demographic variables. More specifically, this study investigated the use of computer mediated conferencing (CMC) tools (i.e., email and electronic discussion boards) and computer aided instructional (CAI) resources (i.e., the computer and Internet) to determine whether they contribute to student learning.
\end{abstract}

The sample utilized in this study consisted of 2000 college students, randomly drawn from the 2003 College Student Experience Questionnaire database. The survey included 53 Likert scale items with reliability ranges from .78 to .88 on each of the composite scales. The analysis of data consisted of four multiple regressions conducted on specific student learning outcomes. The student learning outcomes included four composite scales, measuring student 1) personal and social development, 2) general education gains, 3) intellectual development, 4) science and technology gains, and 3) vocational preparation.

After controlling for student's background variables, the findings of this study revealed that the use of technology in the college classroom does contribute to student learning. The model, including technology variables, explained $4 \%$ to $7 \%$ of the gains in student learning, while student background variables contributed an additional $.03 \%$ to $2 \%$ of the gains. These findings, though modest, suggest that incorporating technologies in the college classroom can aid students in the learning process.

\section{KEY WORDS}

Learning Engagement, Computer Mediated Instruction, Higher Education, Instructional Technology, Learning Outcomes

\section{INTRODUCTION}

Advances in technology have created new channels for faculty-student interaction. Faculty members are becoming increasingly reliant on web-based technology as a resource for communication and a 
supplement to course instruction. A study of technology in higher education in 2000 revealed that $60 \%$ of all college courses utilized electronic mail, as compared to 20.1\% in 1995 [1]. A similar increase occurred in faculty use of the world-wide-web. This same study showed that $43 \%$ of college instructors used web resources as a component of their syllabus, as compared to just $11 \%$ in 1995 . These types of courses are referred to as "web enhanced" because they incorporate both traditional and electronic approaches to teaching and learning.

Even with the tremendous growth in the use of web-based technologies in traditional college courses, the provision of new instructional tools for classroom instructors, and the innovative course scheduling options offered to students, not much attention has been paid to the effectiveness of these new technologies in contributing to the college classroom experience. Few studies have examined whether these new pedagogical tools increase actual learning. As a result of this lack of attention to the effectiveness of new technologies, there has been a surge in research that examines the impact of technology on student performance. The growth of this research related movement started in the 1980s. In the early research, theoretical principles related to educational technology were resisted in the analysis of both the research and data [2]. This study examines the actual effects of web-based technology on student outcomes utilizing a constructivist framework for analysis.

\section{THEORETICAL FRAMEWORK}

Since the late 1970s, constructivism has become one of the most well known and widely used theories of learning and has served as a framework for the study of learning in educational research. Constructivism in learning theory suggests that learners develop understanding through their own beliefs grounded in their background and knowledge base, past experiences, and new experiences. A constructivist view of learning rests on the assumption that knowledge is constructed by learners as they attempt to make sense of their environments. Learners must interpret and transform complex information based on their own knowledge and experiences. The metaphors of carpentry or architecture can be used to portray the constructivists emphasis on a dynamic process of individual development of understanding through building, shaping, and configuring meaning [3].

The emphasis of constructivist teaching is very different from the more traditional classroom lecture model, where lecturers seek to directly convey knowledge to students. Constructivism is based on the fundamental assumption that people create knowledge from the interaction of their beliefs, their existing knowledge, and the new ideas they encounter. Constructivists recognize the need to foster interaction between students and instructors. In the constructivist classroom, active student participation, peer interaction, critical thinking, and reflection are keys to learning. Additionally, collaboration is an integral component of the learning process. Within the schema of the constructivist model, learning becomes a communal activity that includes a focus on sharing cultural knowledge. Collaborative experiences provide students an opportunity to share understandings of course content, which promotes exposure to multiple perspectives. This additional exposure can, potentially, result in enhanced comprehension of course related materials.

Web-based technologies act as tools that assist learners in knowledge discovery and as conduits for collaboration. In essence, they aid two of the key principles of constructivism. Web-based technologies support constructivist environments by assisting students in gaining a clearer understanding of key concepts and ideas by providing access to multiple data and information sources. Through the Internet, learners are able to work interactively to discover rich resources that enable them to solve problems or construct knowledge. Similarly, computer mediated conferencing tools facilitate student collaboration and provide new pathways for learner communication and interaction. This can be done using synchronous 
and asynchronous communications where participants share information in pursuit of meaning and construction of knowledge [4].

\section{FACULTY AND STUDENT COMPUTER MEDIATED INTERACTIONS AND LEARNING OUTCOMES}

Research on faculty/student interaction tends to focus on the traditional face-to-face mode of communication. Fewer studies focus on newer technologies, such as email. Even so, the literature related to these new communication technologies is expanding, and their findings appear to be mixed with respect to measuring student performance. For example, some studies reported positive results when teachers maintained daily e-mail contact with students $[5,6]$. The results provide evidence that email can support learner knowledge and skill acquisition, and cognitive growth. Comparable results were also illustrated in Flowers' and Zhang's [7] study of 45,000 undergraduate students in the U. S. The results of this study showed that when students interacted with instructors via e-mail, they showed significant gains in science and technology knowledge, vocational skills development, personal and social development, and writing and thinking skills.

Conversely, some studies have shown no significant gains in student learning through e-mail interaction with instructors. One such study reported that student performance was not significantly impacted by communication technology, regardless of the amount of personalized electronic message posting by course instructors [8]. Though outcomes were not measured by a specific variable such as knowledge gains, Woods' study explored the ways students engaged in academic related activities to produce educational outcomes. More specifically, the study examined the extent to which personalized electronic messaging contributed to students' perceived sense of community, their satisfaction with their overall learning experience, and their establishment of a personal relationship with their instructor. It was recognized that regardless of the number of personal electronic messages sent to students throughout the semester, there was no statistically significant difference in perceptions between groups that received personalized emails and those who did not. These findings stand in contrast to studies conducted by $\mathrm{Hu}$ and $\mathrm{Ku}$ [5], $\mathrm{Yu}$ and $\mathrm{Yu}[6]$, and Flowers and Zhang [7].

Haworth [9] took a similar approach to Woods [8] to investigate the effectiveness of sending frequent personalized electronic messages to students. The findings of this study suggest that messages contribute little to the amount of student participation in class discussions. Increased use of personalized messages was seen as complementary communication by students who only sent one or two messages during the semester. It appeared that the use of electronic messages did not significantly increase student-to-faculty interaction but redistributed the contact to an alternative form. Similarly, Haworth [9] and Woods [8], Gatz and Hirt [10] reported that their sample of traditional-age, residential, first-year students ( $\mathrm{n}=23$ ) used email quite extensively, but only a limited amount of their correspondence enhanced students' ability to academically or socially integrate into their environment. Findings related to the effectiveness of learning through the use of email appear to be mixed, though there are slightly more studies showing the use of email can improve learning. The unresolved nature of these findings suggests that further exploration is warranted.

\section{COMPUTER ASSISTED INSTRUCTION AND LEARNING OUTCOMES}

Computer Assisted Instruction is an interactive instructional technique that utilizes a computer to present instructional material, monitor learning, and select additional instructional material in accordance with 
individual learner needs. CAI might also include Computer Supported Learning Resources (CSLR) which is the use of a computer as an access point for information. CSLR is a tool used by a learner in the learning process. In general, the literature suggests that the use of Computer Assisted Instruction (CAI) such as computer-based applications and the Internet, produce achievement effects superior to those produced through traditional instructional techniques $[11,12,13]$. These findings hold true for students of differing ages, abilities, and academic foci.

Some researchers have compared the effects produced by different forms of computer-based instruction (sometimes alone and sometimes as a supplement to traditional instruction) with the effects of traditional instruction alone $[12,14,15]$. Yaccub [16] conducted a meta-analysis and concluded that on the average, higher gains are produced with CAI instructional methods than with traditional teaching methods. His findings showed that the effect size is likely to almost double from .35 to .64 when CAI is utilized. However, some findings have shown no significant difference between traditional teaching methods and CAI $[17,18,19]$.

It is important to note that it is difficult to compare two different modes of delivery. It seems as though when this is done, it is likely to reveal no significant difference between the two modes [20,21, 22]. Each delivery mode should be viewed as a method to enrich the learning experience. This was best summarized by Dalton and Hannafin [11] who wrote, "while both traditional and computer-based delivery systems have valuable roles in supporting instruction, they are of greatest value when complementing one another" (p. 32). Therefore, instead of comparing media types, it is best to study how a particular instructional strategy adds value to the instructional method being employed. The use of CAI should be examined from the perspective of how it contributes to and enhances the learning environment.

Some studies have shown that CAI increases cognitive growth. One particular study analyzed the use of interactive media as an aid to students in a science course. At the end of the six week unit, there was an overall improvement of $24 \%$ in the number of correct responses, mainly in measures of higher level thinking skills, between pre- and post-tests. The findings revealed observable growth in both social and thinking skills. Media enriched and detailed examples of plant and animal fossils enabled students to better identify and classify them [23].

The use of CAI software has been reported to increase cognitive domain, higher-order thinking skills as well. Thornburg and Pea [24] examined the effect of using two software programs-Interactive Decision Envisioning Aid (IDEA) and Notecards - to train high school students in cognitive strategy and metacognitive strategy. The results showed that after the training in learning strategies from the software program, the breadth and depth of the subjects' argumentation improved significantly when compared to their knowledge and abilities prior to the instruction. Further, two months later subjects were able to retain these cognitive strategies. Though the sample size of the study $(n=10)$ has the effect of weakening its impact, it still provides insight onto instructional design strategies that may have the potential to improve student cognitive performance.

Utilizing different types of software in instructional design can promote different types of interactions and learning outcomes among students [25]. Some researchers suggest that verbal interactions between students when using simulation software facilitate higher-order thinking by promoting peer interaction for problem solving [26]. Flowers and Zhang [7] found that using a computer for word processing, searching for information on the Internet, and analyzing quantitative information resulted in significant gains in writing and thinking skills. Word-processing software has been reported to encourage students to find solutions to a wide range of writing problems when used in a collaborative writing environment that 
encourages extensive discussion [27].

Other researchers have reported that students are able to work longer and develop a better understanding of the writing process by working cooperatively on a writing task [28]. The word-processing environment is ideal for motivating students to discuss, reflect upon, and edit their work within cooperative groups. Additionally, participation and collaboration among students increases when they use computers in groups [29]. Word-processing applications also allow for more fluid, collaborative learning environments which are likely to produce a higher quality of interaction [27]. Users have the ability to add, delete, and rearrange text, allowing more congruency in the writing process than pencil-and-paper approaches. In turn, the use of word processors leads to better writing outcomes than the use of paper-and-pencil or conventional typewriters. Such outcomes include longer writing samples, a greater variety of word usage, a greater variety of sentence structures, more accurate mechanics, better spelling, more substantial revisions, greater responsiveness to teacher and peer feedback, better understanding of the writing process, better attitudes toward writing, and freedom from the problem of illegible handwriting [16, 30, 31].

\section{PURPOSE OF THE STUDY}

The purpose of this study is to determine whether a sample of students who frequently use newer communication tools, such as email threaded discussions, achieve significant gains in learning outcomes. More specifically, this study will examine:

1) The frequency of use of online collaboration (i.e., email, threaded discussions, or relay chat) and whether collaboration contributes significantly to student outcomes.

2) The frequency use of computer assisted instruction (i.e., computer and Internet) and its contribution to student outcomes.

\section{METHODS}

This study utilized data from the 2003 College Student Experiences Questionnaire (CSEQ) database, which is housed at the Center for Postsecondary Research. The CSEQ is a national survey of randomly selected undergraduate students from colleges and universities across the United States. Institutions elect to participate in a paper-based version or a web-based version of the CSEQ survey. This study consists of a secondary data analysis of the web-based version of the 2003 CSEQ.

Invitations to participate in the survey were sent electronically. Student e-mail addresses were gathered from Fall 2002 enrollment data provided by participating institutions. Codes were developed by the agency administering the survey to track participant institutional affiliation. Data collection took place between May 2003 and September 2003. Participating institutions applied to CSEQ to become survey sites. Each institution provided email addresses for its student participants. A general announcement was sent (see Appendix A), inviting students to participate in the survey beginning in February of 2003. The survey web-site was open for three months. A hyperlink was embedded in the text of the email invitation, which directed participants to the instrument. To prevent multiple responses from the participants, students were required to submit contact information (e.g., name, social security number, and phone number), and if duplicates and non registered names were found, they were automatically removed. A follow-up email announcement was sent to non- respondents in April as a reminder. The web-based survey was closed and removed from the internet server in early September of 2003. 
The CSEQ questionnaire is based on extensive research and guided by Chickering and Gamson's (1987) "Seven Principles for Good Practice in Undergraduate Education." The instrument utilized in this study includes 190 Likert-type items that relate to student academic experiences. For the purposes of this study, 53 items were selected from the two scales: 1) Estimate of Educational Gains (general education, personal development, science and technology, intellectual skills, practical and vocational competence) and 2) engagement (student acquaintances). Additional demographic data were collected in the latter sections of the instrument. The demographic variables included age, martial status, gender, race, living situation, educational status, parents' education level, and major field of study. For this study, only the gender, race, and educational level demographic variables were utilized.

The sampling frame for this study included students from various colleges and universities across the United States. The study operationalized a random selection in a sub-sample of 2,000 participants from the total national sample $(n=87,855)$ of students who completed the CSEQ survey in 2003. The random sample was primarily composed of participants who were enrolled in some form of online instruction. The national sample included students enrolled in both online and traditional courses.

A comparison of the random sample and national sample clearly demonstrates the demographic similarities of the two groups. Most of the participants were female (63\%), slightly higher than the national sample (61\%) of women enrolled in four year institutions. Caucasian/White students made up the majority of the sample (78\%), which is somewhat higher than the national sample (76\%). The largest percentage difference between both groups was the enrollment status with a $19 \%$ difference between the random and national sample of freshman and sophomores sampled. Table 1 provides a demographic comparison between the random and national sample of the CSEQ participants.

The questions chosen for analysis in this study were based on a constructivist framework. First, demographic characteristics were analyzed to determine the effect that student background had on student learning outcomes. Second, questions related to student's ability to manipulate technology to expand their sphere of knowledge and to leverage the technology for gains in understanding were studied. Finally, student interaction and collaboration in the learning process were analyzed.

\section{A. Reliability}

Reliability is the consistency of measurement, or the degree to which an instrument measures the same way each time it is used under the same condition with all participants. Another characteristic of a reliable instrument is stability; the degree to which participants respond in similar ways at two different points in time. For this purpose, Cronbach's Alpha was used. It ranges from 0 to 1.0. Scores that are at the higher end of the range (e.g., above .70) suggest that the items in a scale are related.

The Alpha coefficients for the learning outcomes scales range from .78 to .88 , suggesting high reliability. Table 2 outlines the items and internal consistency estimates associated with the student learning outcome scales.

\section{B. Measures}

The measures used in this study will be outlined in two sections: dependent variables and independent variables. 


\section{Dependent Variables}

Five student learning outcomes attributed to the college experience were assessed: 1) personal and social development, 2) general education, 3) intellectual development, 4) science and technology, and 5) vocational preparation. An analysis from the Buros Mental Measurement Yearbooks show that the items on the CSEQ scales are clear, well defined and have face validity, showing that logical relationships exist among same scales items [32].

Items on the questionnaire were measured on a 4 point Likert scale: $4=$ Very Often, $3=$ Often, $2=$ Occasionally, $1=$ Never. Cronbach's alpha estimates for the five scales were: 1) general Education, measured by six items $(\alpha=.79) ; 2)$ gains in intellectual skills, measured by seven items $(\alpha=.80)$; personal and social development measured by five items $(\alpha=.82) ; 4)$ gains in science and technology measured by four items $(\alpha=.89) ; 5)$ and three items measured gains in vocational preparation. $(\alpha=$ .78) Details on item wording, means, standard deviations and descriptive statistics estimates of measures are shown in Table 2.

\section{Independent Variables}

The independent variables or predictors for this study included 1) frequency of interaction via email, 2) frequency of collaborative work online, 3) frequency of computer use to prepare papers or reports, 4) frequency of use of the Internet for course related information. Participants responded to a 4 point scale: 4= Very Often, $3=$ Often, $2=$ Occasionally, $1=$ Never. All independent variables were measured as single items. Details on item wording, descriptive statistics, means, and standard deviation estimates measures are shown in Table 3.

\section{Sets of Correlations}

Inter-scale correlations were conducted on the independent and dependent variables to gain a better understanding of the strength of the scales. The results showed that there were significant correlations among the scales $(\mathrm{p}<.05)$. Correlations for the dependent variables were conducted first to measure learning outcomes. The $\mathrm{r}$ - values ranged from $20 \%-75 \%$, with the majority of the correlations falling within the $27 \%-55 \%$ range, indicating a moderately strong relationship as shown in Table 4 . The scale relating to students' personal and social development and intellectual skills showed the strongest relationship $(\mathrm{r} .=75)$. The scales with the lowest correlations were the social interaction scale and vocational preparation scale $(\mathrm{r}=.201)$.

A second set of correlations was conducted on the independent variables. Results showed moderate to low correlations on using email to communicate while the use of computer word processors presented the highest correlation at $\mathrm{r}=.480$. Using email to communicate with classmates and joining in electronic discussions reported the lowest correlation at $r=.134$. All items showed a positive relationship and were statistically significant $(\mathrm{p}<.01)$ as displayed in Table 5.

\section{DATA ANALYSES}

Data analyses were conducted using SPSS Version 12. Frequencies, descriptive statistics, and distributions were examined for all variables. Histograms, normal probability plots, and scatter plots were also created to determine whether the assumptions of linearity, normality, and homoscedascity were met. Item level analyses were carried out prior to creating the composite variables, and reliability estimates were calculated for each composite. 
Multiple regression statistical analyses were conducted to analyze the data and find the best predictors of the dependent variables as they relate to learning outcomes. Regression was used to determine the contribution of the four interaction and technology use variables, above and beyond the impact of demographic factors, to the prediction of the outcome variables (i.e., learning outcomes).

The variables used in the regression equation were categorical in measure. To meet the assumptions of the model operationalized in this study, it was necessary for the dependent variable to be quantitatively or continuously measured. Dummy coding is the most commonly used coding method used to group data according to categories. Utilizing dummy coding, association in a given group or category was assigned a 1 , whereas non-association in the category was assigned a 0 . Groups that were given a 1 were expected to have higher learning outcome effects. For the purpose of the regression analyses, categorical variables, such as student gender, race, and class were coded as dummy variables. The specifications and the coding of the independent variables are listed below:

Gender. Student gender variable was dummy coded as:

$$
\begin{aligned}
& 0=\text { Male } \\
& 1=\text { Female }
\end{aligned}
$$

Race. The race variable is dichotomized into Whites and non-Whites because of the low percentage of minorities represented in the sample. It was dummy coded as:

$$
\begin{aligned}
& 0=\text { Non-White } \\
& 1=\text { White }
\end{aligned}
$$

Class level. In this study, the class level variable is coded into two categories:

Lower - mid level (freshmen, sophomores, and juniors) and seniors. The variables were coded as:

$$
\begin{aligned}
& 0=\text { Freshmen, Sophomore, Junior } \\
& 1=\text { Senior }
\end{aligned}
$$

After coding the dummy variables, independent variables were entered in two blocks for each regression analysis. The demographic variables were entered into the first block, and then the group of interaction and technology use variables were entered into the second block. Thus, the independent contribution of each of the interaction and technology use variables could be estimated.

This study was based on the central assumptions that a) frequent use of computer mediated conferencing tools for collaborative interaction would result in greater learning outcomes, and that b) frequent use of computer assisted instruction would result in greater learning outcomes when demographic characteristics have been controlled.

\section{RESULTS}

As expected, the findings revealed that the use of technology does assist in explaining a significant amount of variance in learning outcomes, when demographic characteristics are held constant. For the data analysis both the unstandardized and standardized regression coefficients are reported in the tables. The interpretability of the unstandardized coefficients is somewhat challenging because the measures are truly not interval measures. Interval variables are equally spaced and have to represent equal magnitudes. It is unlikely that the unstandardized coefficients from the scale used $(1=$ never to $4=$ very often) would yield equal magnitude (e,g., there could be more gains from moving from never to occasionally than from 
The Effect of Computer Mediated Conferencing and Computer Assisted Instruction on Student Learning Outcomes

often to very often); therefore, the standardized coefficients will be used to gauge the relative importance of the independent variables in the explanation of student learning outcomes.

\section{REGRESSION MODELS FOR STUDENT LEARNING OUTCOMES}

The focus of this study was the effect of CMC and CAI on student learning outcomes, after controlling for background variables. The five student learning outcome variables were regressed against the student background factors and technology use variables. The technology use variables were general education gains, personal and social development gains, intellectual gains, science and technology gains, and vocational gains. The regression models for student learning outcomes are summarized in Table 6 .

The first regression model measures the contribution the use of technology made to students' general educational outcomes, revealing that background variables explain $.003 \%$ of student learning. Contrary to initial expectations, the background variables do not make a significant contribution to gains in general education. When technology variables are added to the model, there is an $\mathrm{R}^{2}$ change of $4 \%$. Of the technology use variables, frequency of participation in electronic classroom discussions has the greatest effect on general education gains $(B=.11)$, followed by searching the internet for course material $(B=.10)$. The background and use of technology variables together explain about $5 \%$ of the total variance in general education gains $(\mathrm{p}<.001)$.

When examining learning outcome variables, the student characteristics of being white and being a senior appear to be fairly consistent. Background variables have a relatively small effect on student learning outcomes $(.008 \%-2.0 \%)$ for each of the five models. There is a slight negative association with being white in relation to each of the learning outcome variables, though none of the beta values are statistically significant. In contrast, being a senior is positively associated with all of the learning outcome variables. Three of these associations are significant (i.e., personal and social development, intellectual gains, and vocational gains). Being female is found to be positively associated with gains in personal and social development. There is also a negative relationship between being a female and gains in the area of science and technology. This negative relationship was found to be significant.

When the CAI technology related variables are included in the models, the resulting effects are fairly consistent across all of the learning outcome variables. Both searching the Internet and participating in electronic class discussion are key variables that help explain learning outcomes. In all five models, $\mathrm{R}^{2}$ change was modest $(3 \%-7 \%)$ and statistically significant, indicating that the frequency of technology use does indeed contribute to the explanation of gains in student learning after controlling for background or demographic factors.

\section{DISCUSSION}

The researchers assumed that frequency of technology use would explain learning outcomes after controlling for background characteristics. The findings show that this assumption held true. In fact, the use of technology explained nearly four times as much of the variance in student learning as background variables. However, the relative effect of technology on student learning gains is not as great as initially assumed. Nonetheless, the learning outcomes percentage gain of 3-9 percent does provide a modest explanation of the effects of technology on learning within the context of educational psychology.

In the area of learning cognition, many factors contribute to student learning. Key areas that contribute to learning include teacher/instruction related variables [33], student-related variables [34], personal 
characteristics [35], learning styles [36], and environmental elements [37]. Yet, by most standards, the ability of learning tools and/or resources to contribute to learning suggests a need for a regression model that focuses on learning gains. The effectiveness of learning technology tools combined with traditional instruction have typically contributed moderately to the overall gains in learning $[31,38]$.

\section{TECHNOLOGY AND ITS INFLUENCE ON LEARNING OUTCOMES}

\section{A. Computer Mediated Learning Tools}

When taking into account only the use of computer mediated learning tools (email and electronic discussion), the findings in this study showed each was effective in explaining gains in learning outcomes (i.e., general education, personal and social development, intellectual growth, science and technology, and vocational gains). The findings of this study suggest that the utilization of collaborative learning tools modestly supports students in their learning processes. Additionally, collaborative learning tools facilitate discussion, and interaction among students and faculty.

The electronic discussion boards allow students to become active participants and they encourage both reflection and interaction [29]. Previous studies on collaborative learning have reported a moderate to strong relationship between various modes of collaboration and student performance [39, 40]. A possible explanation for the positive association between CMC utilization and learning gains is the effectiveness and ease of its use. More specifically, CMC allows discussions to be easily transmitted, stored, archived, reevaluated, edited, and rewritten. In addition, students enjoy a level of comfort with the more candid nature of CMC when sharing and discussing personal information that they may not in a face-to-face format. Thus, CMC can improve the overall quality of discourse [5, 41].

Studies of the contribution of CMC to learning by type of media have not shown strong evidence to support one mode of delivery over another. However, the findings from this study record only one significant relationship in learning gains through the use of email, and it was specific to personal and social gains. Both Haworth [9] and Woods [8] found the use of email to have positive effects on student academic and social integration. Though the methodologies of their studies are different, Haworth investigated online students and the types of messages sent while Woods examined online students and the frequency of messages sent, they both showed email having moderate effects as a learning tool. The results of this study showed that electronic discussions were more effective than email in explaining learning gains. Both electronic discussion boards and email are modes of asynchronous communication with similar user control features. The major difference between the two is that electronic discussion boards are centralized and controlled by the sender while email is decentralized--typically remotely located on the end users personal computer though still controlled by the sender.

The use of email is a favored communication tool for students who had an average mean score of 3.74 on a 4 point scale on the instrument used for this study. This score indicates that students used this method of communication very often. The electronic discussion boards had an average mean of 2.05, showing that students occasionally used this method. Although students' demonstrated a preference for email, it is possible that email is being used more for social communication than for academics. Additional evidence of this conclusion comes from this study's findings that students who use email show significant gains in the area of personal and social development and did not show gains in any other learning outcome area besides relatively small gains in science and technology. Though only a general conclusion can be drawn from this one finding, it does reveal a possible pattern. Additional research is warranted to gain a better understanding of why differences in effectiveness may exist between these two modes of electronic 
communication when examining learning gains.

\section{B. Computer Assisted Instruction}

Two additional modes of technology investigated are classified as CAI tools (i.e., use of the computer word processor and the Internet). CAI tools allow learners to discover knowledge at their own pace. This is considered an exploratory form of learning. The Internet is a key piece of CAI related exploratory learning, allowing learners to search, retrieve, and evaluate information as it is displayed and permitting users to be in control of their quest for information. Findings from this study reveal that the use of the Internet is a moderate contributor to actual student learning outcomes. Searching the Internet has the greatest effect on three of the five learning constructs.

Though the effect size is moderate, the findings suggest that the Internet can be a somewhat effective tool in facilitating student learning. This finding is fairly consistent with other studies which showed that using the Internet allowed exploratory learning to occur that improved student academic performance [6, 7, 38]. Positive effects are likely to be associated more closely with ease of access and retrieval of educational resources on the Internet [6]. As the quality and abundance of resources on the Internet grow, it is likely that more positive learning gains may be seen.

It is somewhat surprising for the researchers not to find a significant relationship between the variable of computer use and learning, particularly since it is the most popular learning tool of all the technology variables. The use of a computer for projects or reports yielded the highest mean score (3.83 on a 4.0 scale) out of all the technology resources, showing that computers are frequently used learning resources for students. The impact computers can have on learning is further supported by other studies which have found that computers aide students in their cognitive growth $[30,42,43]$.

The lack of effect of computer use on learning gains is likely due to its association to the term "word processor." Because "word processor" was a separate independent variable and carried with it the suggestion that it enables learners to write papers for classes, this definition could have affected student responses on computer use. Students may use a word processor to write on topics such as politics and diversity, but not necessarily use to interact with faculty and other students, thus engaging in learning related activities. Students may use a computer word processing system to write papers and not necessarily use it as an interactive learning tool.

Some of the questions that measure learning outcomes revolve around the actions of search, retrieval, or interaction. The use of a computer does not necessarily provide an outlet for interaction unless a particular type of software is adopted to facilitate this process. For example, one of the questions that measures general education gains asked students to rate their efforts in developing an understanding and enjoyment of art, music, and drama. If students associated a computer with word processing, then it would be difficult for them to develop an appreciation for the arts because word processors are not used for this function. Quite the opposite is true for using the Internet. The Internet provides the capability to explore, view, and listen to files associated with the arts. A computer can have these same capabilities if the software permits. Because students may have associated the computer as just a word processing tool, the responses were likely distorted.

A second possible reason the use of a computer did not play a significant role could be a reflection of the instructional design, though this is a speculative assumption. This study was not designed to examine how technology is being used as an instructional strategy; however, it is known that simply providing learners 
with hyperlinks to various websites will not yield productive results [44]. There must be an incorporation of instructional design principles, (i.e. content and learner analyses) to determine what students should know and be able to do with information [45]. Therefore, if proper instructional guidelines are not applied, it is unlikely that any measurable learning will result.

\section{IMPLICATIONS}

The findings of this study have two immediate implications for instructional practice. First, the findings reveal that the use of electronic communication and computer-based resources provide complementary learning activities that aid the learning process. There is great interest and potential in web-based, flexible, learning with over 60 percent of instructors incorporating some form of technology as a part of their instruction [1]. While instructors are the focal point in most course settings, it should be noted that complementary learning activities are just as, if not more, important for practice. Research has proven that most learning occurs outside of the classroom environment and is strongly correlated with academic effort $[46,47]$. Technology based learning resources provide important support in the classroom and complement what is being taught. Teachers should utilize technology-based resources to help learners be creators of knowledge through information research and content evaluation. These types of skills assist learners in becoming critical explorers rather than passive observers.

A second implication, related to instructional practice, is the need to select the appropriate media and to decide on the frequency of its use. Both the media and the frequency of use have the potential to enhance student learning outcomes if chosen and managed properly. Technologies that are capable of engaging students in interactive discussion with the instructor, peers, or an academic community can improve learning. Email and discussion boards were seen as the most effective technologies for facilitating interactive discussions. However, there must be a concentrated effort to develop strategies that promote subject matter relevant dialogue during the instruction development phase. These strategies need to take into account the frequency of access to, and duration of time spent on course content. Since in-class instruction is often limited, efforts should be made to encourage out of class learning activities that challenge students to probe, explore, clarify, explain, evaluate, and analyze written content with others. This provides student users the opportunity to learn from one another, using collaborative learning methods.

\section{IMPLICATIONS FOR FUTURE RESEARCH}

There are many opportunities for new studies on computer and web-based learning utilizing the constructivist theory as a general guideline. However, for the purpose of this study, two specific opportunities will be discussed. First, there is a need to examine other variables to advance the research in this area. Though finding good fitting prediction models was not the intention of this study, the models used herein had a relatively low R-square; that is, the independent variables and the control variables together only explained a small portion of the variances in learning outcomes. This relationship suggests that there might be other variables that have more significant effects on learning, which were are not included in the models used.

A second study to follow up on some unanswered questions regarding the definition of computer use would clarify any misconceptions between a word processor and computer. A computer serves as an electronic device that can store, retrieve, and process data. More important, perhaps, is to the need to clarify the differences in a computer and the software that can be used to complete certain tasks. Today, there are thousands of programs that enable computers, to design, to store, and to manipulate data in a manner that makes it easy for an individual to see them as one unit. It is very rare to purchase a computer 
The Effect of Computer Mediated Conferencing and Computer Assisted Instruction on Student Learning Outcomes

without any preinstalled software. Therefore, a follow up study would clarify any definitions or terms to ensure that there is a direct correlation between computer use and the task it enables users to complete.

\section{REFERENCES}

1. Green, K. The 2000 National Survey of Information Technology in Higher Education. The Campus Computing Project, 2000.

2. Clark, R. E. Reconsidering research on learning from media. Review of Educational Research 53: 445-459, 1983.

3. Vygotsky, L. S. Mind and society: The development of higher psychological processes. Cambridge MA: Harvard University Press, 1978.

4. Jonassen, D. Designing constructivist learning environments. In C. Reigeluth (Ed.), Instructional design theories and models: A new paradigm of instructional theory, vol. II, 215-239. Mahwah, NJ: Lawrence Erlbaum Associates, 1999.

5. Yu, F. and $\mathbf{H}$. Yu. Incorporating e-mail into the learning process: its impact on student academic achievement and attitudes. Computers and Education. 38: 117-126, 2002.

6. Hu, S. and G. D. Kuh. Computing experience and good practices in undergraduate education: Does the degree of campus "wiredness" matter? Education Policy Analysis Archives. 9: 2001.

7. Flowers, L. and Y. Zhang. Racial differences in information technology use in college. College Student Journal 37: 235-241, 2003.

8. Woods, R. H. How much communication is enough in online courses? Exploring the relationship between frequency of instructor-initiated personal email and learners' perceptions of and participation in online learning. International Journal of Instructional Media 29: 377-395, 2002.

9. Haworth, B. An analysis of the determinants of student e-mail use. Journal of Education for Business 75: 55-60, 1999.

10. Gatz, L. B. and J. B. Hirt. Academic and social integration in cyberspace: Students and e-mail. Review of Higher Education 23: 299-318, 2000.

11. Dalton, D. and M. J. Hannafin. The effects of computer-assisted versus traditional mastery methods on computation accuracy and attitudes. Journal of Educational Research 82: 27-33, 1988.

12. Schacter, J. and C. Fagnano. Does computer technology improve student learning and achievement? How, when, and under what conditions? Journal of Educational Computing Research 20: 329-43, 1999.

13. Fletcher, J. D. The effectiveness of interactive videodisc instruction in defense training and education. Institute for Defense Analyses: Alexandria, VA, 1990.

14. Kini, A. S. Effects of cognitive style and verbal and visual presentation modes on concept learning in CBI. Presented at Annual Meeting of the American Educational Research Association, New Orleans, LA, 1994.

15. Wells, J. G. Effects of an on-line computer-mediated communication course, prior computer experience and Internet knowledge, and learning styles on students' Internet attitudes. Journal of Industrial Teacher Education 37: 22-53, 2000.

16. Yaakub, M. N. Meta-analysis of the effectiveness of computer-assisted instruction in technical education and training. Dissertation, Virginia Polytechnic Institute and State University 1998.

17. Hays, R. T., J. W. Jacobs, C. Prince, and E. Salas. Flight simulator training effectiveness: A metaanalysis. Military Psychology 4: 63-74, 1992.

18. T., E. Kisling, W. Cai, B. M. Yu, F. Giles, and J. P. Brown. Impact of navigational models on task completion in web-based information systems. Indiana ED 436 141, 1999.

19. Koner, B. C., M. Lamsal, and B. D. Banerjee. Conventional teaching remains effective in teaching medical biochemistry in BPKIHS, Nepal, although students enjoy supplementary computer teaching. Biochemistry and Molecular Biology Education 29(4): 137-141, July 2001. 
20. Clarke, W. R. The effects of computerized instruction on the improvement and transfer of math skills for low-skilled and below average-skilled sophomore students, considering student gender, ethnicity, and learning style preferences. University of La Verne, 1993.

21. Astleitner, H. Teaching critical thinking online. Journal of Instructional Psychology 29: 53-76, 2002.

22. Sperling, R. A., M. Seyedmonir, and M. Aleksic. Animations as Learning Tools in Authentic Science Materials. International Journal of Instructional Media 30: 213-21, 2003.

23. Henderson, L., Y. Eshet, and J. Klemes. Under the microscope: factors influencing student outcomes in a computer integrated classroom. The Journal of Computers in Mathematics and Science Teaching 19: 211-236, 2000.

24. Thornburg, D. and R. Pea. Synthesizing instructional technologies and educational culture: Exploring cognition and metacognition in the social studies. Journal of Educational Computing Research 7: 121-164, 1991.

25. Tuovinen, J. E. Multimedia distance education interactions. Educational Media International 37: 16-24, 2000.

26. Cradler, J., M. McNabb, M. Freeman, and R. Burchett. How does technology influence student learning? Learning \& Leading with Technology 2: 46-56, 2002.

27. Chan, M. No Talking, please, just chatting: Collaborative writing with computers. Presented at Teaching in the Community Colleges Online Conference, Innovative Instructional Practices, Honolulu, HI, 1997.

28. Hsiu-Mei, H. Toward constructivism for adult learners in online learning environments. British Journal of Educational Technology 33: 27-37, 2002.

29. Warschauer, M. Computer-mediated collaborative learning: Theory and practice. The Modern Language Journal 81: 470-481, 1997.

30. Henke, M. E. The Effects of Three methods of Computer-Based Instruction (CBI) On Psychomotor Performance of College Students. Dissertation submitted to the Graduate Faculty of Virginia Polytechnic Institute and State University, 1997. http://scholar.lib.vt.edu/theses/available/etd16409449701231/unrestricted/etd1.pdf.

31. Cotton, K. Computer-Assisted Instruction. 1991. http://www.nwrel.org/scpd/sirs/5/cu10.html.

32. Gonyea, R. M., K. A. Kish, G. D. Kuh, R. N. Muthiah, and A. D. Thomas. College Student Experiences Questionnaire: Norms for the Fourth Edition. Bloomington, IN: Indiana University Center for Postsecondary Research, Policy, and Planning, 2003.

33. Bradley, C., K. A. Kish, A. M. Krudwig, T. Williams, and O. S. Wooden. Predicting facultystudent interaction: An analysis of new student expectations. Journal of the Indiana University Student Personnel Association: 72-85, 2002 edition. http://www.indiana.edu/ iuspa /Journal/2002/Journal2002.pdf.

34. Winteler, A. Differential validation of a path analytic model of university dropout. Presented at Annual Meeting of the American Educational Research Association, San Francisco, CA, 1986.

35. Ting, S. M. R. Predicting first-year grades and academic progress of college students of firstgeneration and low-income families. Journal of College Admission 158: 14-23, 1998.

36. Dunn, R. and K. Dunn. Teaching secondary students through their individual learning styles: Practical approaches for grades 7 - 12. Boston: Allyn \& Bacon, 1993.

37. Outcalt, C. L. and T. E. Skewes-Cox. Involvement, Interaction, and Satisfaction: The Human Environment at HBCUs, 2002.

38. Kekkonen-Moneta, S., and G. B. Moneta. E-Learning in Hong Kong: comparing learning outcomes in online multimedia and lecture versions of an introductory computing course. British Journal of Educational Technology 33(4): 423-33, 2002.

39. Kwok, R. C. W., and J. Ma. Use of a group support system for collaborative assessment. Computers \& Education 32: 109-125, 1999.

40. Teague, M., J. Talbot, and A. M. Ward. Evaluation of a pilot project to use computers in a rural general practice term. Australian Journal of Rural Health. 8: 305-310, 2000. 
41. Hinkle, S. E. The impact of e-mail use on student-faculty interaction. Journal of the Indiana University Student Personnel Association: 27-34, 2002.

42. Flowers, L., T. E. Pascarella, and T. C. Pierson. Information technology use and cognitive outcomes in the first year of college. The Journal of Higher Education 71: 637-666, 2000.

43. Simon, S. J. The relationship of learning style and training method to end-user computer satisfaction and computer use: A structural equation model. Information Technology, Learning, and Performance Journal 18: 41-59, 2000

44. Zhao, Y. Design for adoption: The development of an integrated web-based education environment. Journal of Research on Computing in Education 30: 28-44, 1998.

45. Dick, W., L. Carey, and J. O. Carey. The systematic design of instruction, 5th ed. New York: Longman, 2001.

46. Pascarella, E. T., and P. T. Terenzini. How college affects students. San Francisco: Jossey-Bass, 1991.

47. Kuh, G. D., and H. Shouping. The relationship between computer and information technology use, selected learning and personal development outcomes, and other college experiences. Journal of College Student Development 42: 217-232, 2001. 
The Effect of Computer Mediated Conferencing and Computer Assisted Instruction on Student Learning Outcomes

Table 1. Characteristics of CSEQ 2003 Sample

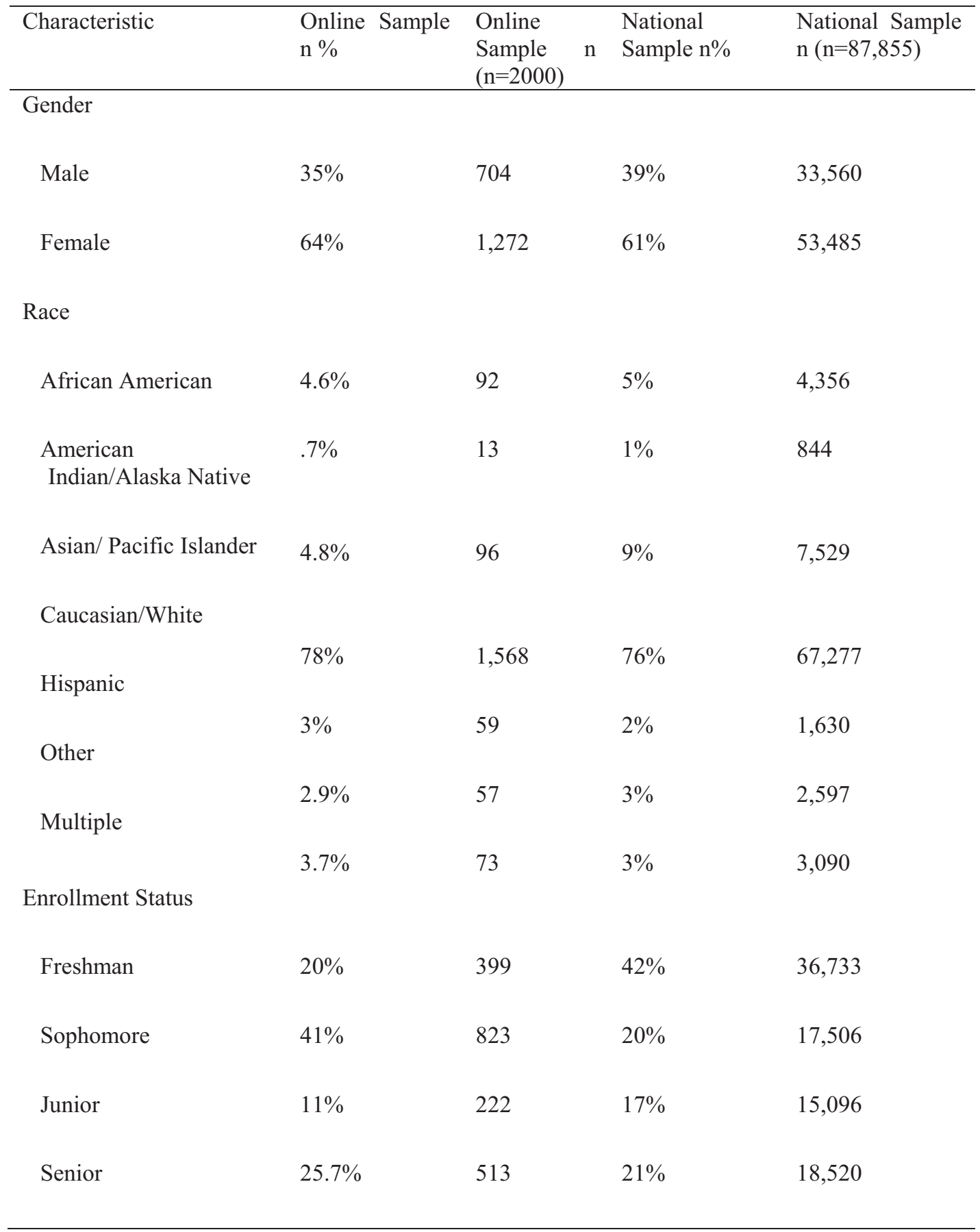


The Effect of Computer Mediated Conferencing and Computer Assisted Instruction on Student Learning Outcomes

Table 2. Items and descriptive statistics for learning outcomes

Items and descriptive statistics for learning outcomes

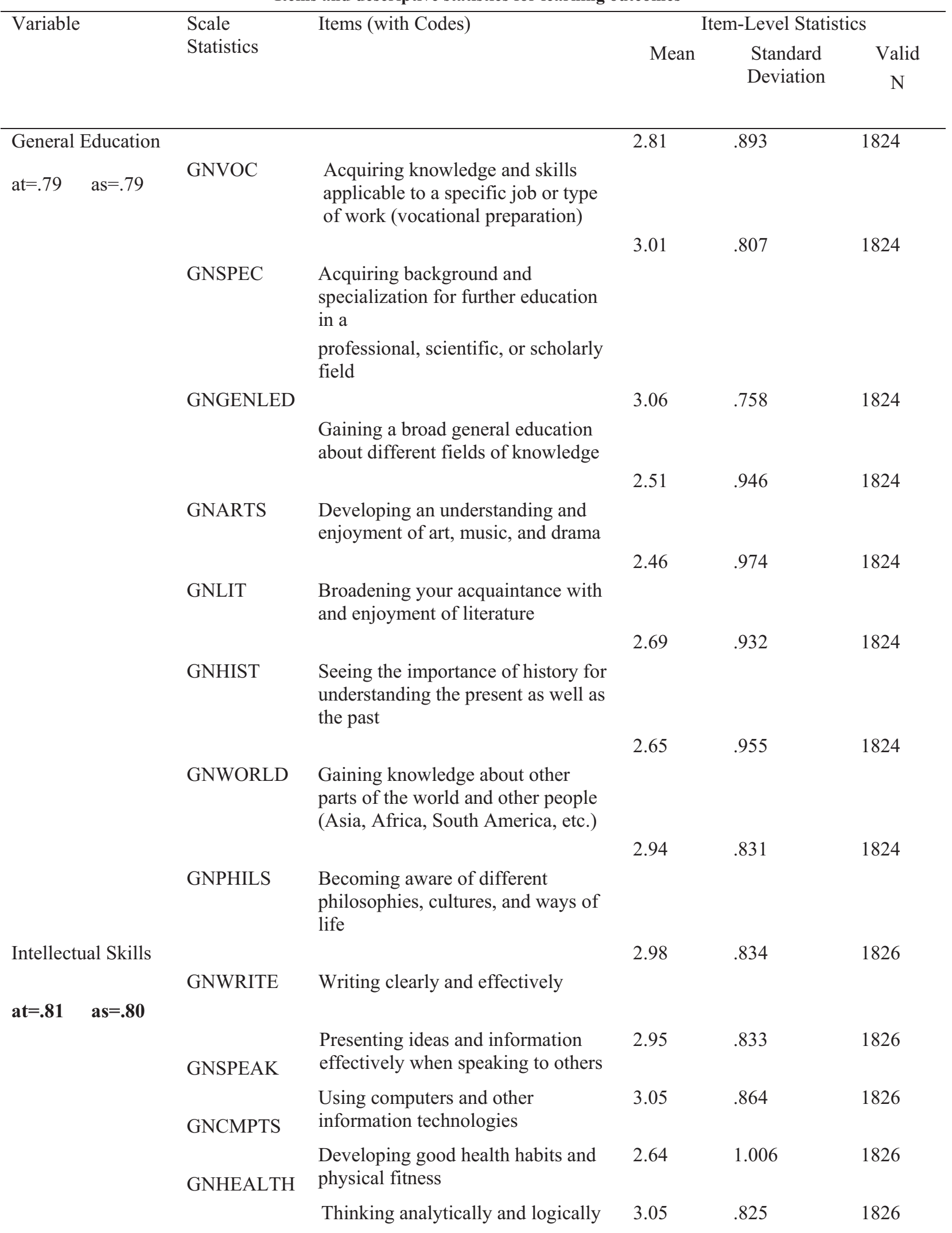


GNANALY

GNSYNTH

Putting ideas together, seeing

$3.14 \quad .765$

1826

relationships, similarities, and

differences between ideas

$\begin{array}{lll}3.28 & .755 \quad 1826\end{array}$

GNINQ Learning on your own, pursuing

ideas, and finding information you

need

Note: at is the alpha for the national sample and as is the alpha for the sub-sample.

Table 2 (Continued)

\begin{tabular}{|c|c|c|c|c|c|}
\hline \multirow[t]{2}{*}{ Variable } & \multirow{2}{*}{$\begin{array}{l}\text { Scale } \\
\text { Statistics }\end{array}$} & \multirow[t]{2}{*}{ Items (with Codes) } & \multicolumn{3}{|c|}{ Item-Level Statistics } \\
\hline & & & Mean & $\begin{array}{c}\text { Standard } \\
\text { Deviation }\end{array}$ & Valid N \\
\hline $\begin{array}{ll}\text { Personal and } \\
\text { Social } & \\
\text { Development } & \end{array}$ & GNVALUES & $\begin{array}{l}\text { Developing your own values and } \\
\text { ethical standards }\end{array}$ & 3.18 & .828 & 1834 \\
\hline \multicolumn{6}{|l|}{ at $=.83 \quad$ as $=.82$} \\
\hline & GNSELF & $\begin{array}{l}\text { Understanding yourself, your } \\
\text { abilities, interests, and personality }\end{array}$ & 3.31 & .717 & 1834 \\
\hline & GNOTHERS & $\begin{array}{l}\text { Developing the ability to get along } \\
\text { with different kinds of people }\end{array}$ & 3.21 & .778 & 1834 \\
\hline & GNTEAM & $\begin{array}{l}\text { Developing the ability to function as } \\
\text { a member of a team }\end{array}$ & 3.03 & .862 & 1834 \\
\hline & & Learning to adapt to change & 3.18 & .787 & 1834 \\
\hline & GNADAPT & & & & \\
\hline \multirow{4}{*}{$\begin{array}{l}\text { Science and } \\
\text { Technology } \\
\mathbf{a t}=\mathbf{8 7} \quad \mathbf{a s}=\mathbf{. 8 9}\end{array}$} & GNSCI & $\begin{array}{l}\text { Understanding the nature of science } \\
\text { and experimentation }\end{array}$ & 2.36 & .983 & 1849 \\
\hline & GNTECH & $\begin{array}{l}\text { Understanding new developments in } \\
\text { science and technology }\end{array}$ & 2.40 & .962 & 1849 \\
\hline & GNCONSQ & $\begin{array}{l}\text { Becoming aware of the } \\
\text { consequences (benefits, hazards, } \\
\text { dangers) of new applications of } \\
\text { science and technology }\end{array}$ & 2.44 & .943 & 1849 \\
\hline & GNQUANT & $\begin{array}{l}\text { Analyzing quantitative problems } \\
\text { (understanding probabilities, } \\
\text { proportions) }\end{array}$ & 2.58 & .973 & 1849 \\
\hline $\begin{array}{l}\text { Vocational } \\
\text { Preparation }\end{array}$ & GNCAREER & Gaining a range of information that & 3.06 & .782 & 1848 \\
\hline
\end{tabular}


at $=.78$ as $=.78$

GNVOC Acquiring knowledge and skills

$\begin{array}{lll}2.81 & .983 & 1848\end{array}$

applicable to a specific job or type

of work (vocational preparation)

$\begin{array}{lll}3.01 \quad .809 & 1848\end{array}$

GNSPEC Acquiring background and

specialization for further education

in a

professional, scientific, or scholarly

field

Note: at is the alpha for the national sample and as is the alpha for the sub-sample.

Table 3. Items and Descriptive Statistics for Independent Variables

Items and descriptive statistics for independent variables

\begin{tabular}{|c|c|c|c|c|}
\hline $\begin{array}{c}\text { Independent } \\
\text { Variables }\end{array}$ & Items & Mean & $\begin{array}{c}\text { Standard } \\
\text { Deviation }\end{array}$ & $\begin{array}{c}\text { Valid } \\
\mathrm{N}\end{array}$ \\
\hline $\begin{array}{l}\text { Frequency of } \\
\text { interaction via } \\
\text { email }\end{array}$ & $\begin{array}{l}\text { Used email to communicate with an } \\
\text { instructor or other students }\end{array}$ & 3.74 & .567 & 1903 \\
\hline $\begin{array}{l}\text { Frequency of } \\
\text { collaborative } \\
\text { online Work }\end{array}$ & $\begin{array}{l}\text { Participated in class discussions using an } \\
\text { electronic media (email, list serve, chat } \\
\text { group, etc.) }\end{array}$ & 2.05 & 1.045 & 1903 \\
\hline $\begin{array}{l}\text { Frequency of } \\
\text { computer use to } \\
\text { prepare papers or } \\
\text { reports }\end{array}$ & $\begin{array}{l}\text { Used a computer or word processor to } \\
\text { prepare reports or papers }\end{array}$ & 3.83 & .471 & 1903 \\
\hline $\begin{array}{l}\text { Frequency of } \\
\text { Internet use for } \\
\text { course related } \\
\text { information }\end{array}$ & $\begin{array}{l}\text { Searched the World Wide web or Internet } \\
\text { for information related to a course }\end{array}$ & 3.51 & .723 & 1903 \\
\hline
\end{tabular}


The Effect of Computer Mediated Conferencing and Computer Assisted Instruction on Student Learning Outcomes

Table 4. Correlations among Dependent Variables

Correlations among Dependent Variables $(N=1921)$

\begin{tabular}{|c|c|c|c|c|c|}
\hline Dependent Variables & $\begin{array}{c}\text { General } \\
\text { Education Scale }\end{array}$ & Voc Scale & Sci. Tech Scale & $\begin{array}{l}\text { Per. Soc. } \\
\text { Scale }\end{array}$ & $\begin{array}{l}\text { Intellectual } \\
\text { Skills Scale }\end{array}$ \\
\hline General Education Scale & 1 & & & & \\
\hline Voc. Scale & $.607 * *$ & 1 & & & \\
\hline Sci. Tech Scale & $.368 * *$ & $.438^{* *}$ & 1 & & \\
\hline Per. Soc. Scale & $.541 * *$ & $.489^{* *}$ & $.410 * *$ & 1 & \\
\hline Intellectual Skills Scale & $.595^{* *}$ & $.526^{* *}$ & $.534^{* *}$ & $.749 * *$ & 1 \\
\hline
\end{tabular}

** Correlation is significant at the 0.01 level (2-tailed).

Table 5. Correlations among Independent Variables

Correlations among Independent Variables $(N=1921)$

\begin{tabular}{|c|c|c|c|c|}
\hline $\begin{array}{l}\text { Independent } \\
\text { Variables }\end{array}$ & $\begin{array}{c}\text { Used } \\
\text { computer/word } \\
\text { processor for } \\
\text { paper }\end{array}$ & $\begin{array}{l}\text { Used email to } \\
\text { communicate with } \\
\text { class }\end{array}$ & $\begin{array}{l}\text { Joined in } \\
\text { electronic class } \\
\text { discussions }\end{array}$ & $\begin{array}{l}\text { Searched Internet } \\
\text { for course material }\end{array}$ \\
\hline $\begin{array}{l}\text { Used } \\
\text { computer/word } \\
\text { processor for } \\
\text { paper }\end{array}$ & 1.00 & & & \\
\hline $\begin{array}{l}\text { Used email to } \\
\text { communicate with } \\
\text { class }\end{array}$ & $.480 * *$ & 1.00 & & \\
\hline $\begin{array}{lr}\text { Joined } & \text { in } \\
\text { electronic } & \text { class } \\
\text { discussions } & \end{array}$ & $.134 * *$ & $.192 * *$ & 1.00 & \\
\hline $\begin{array}{l}\text { Searched } \text { Internet } \\
\text { for } \\
\text { material }\end{array}$ & $.346^{* *}$ & $.412 * *$ & $.279 * *$ & 1.00 \\
\hline
\end{tabular}

$* * \mathrm{p}<.01$ 
The Effect of Computer Mediated Conferencing and Computer Assisted Instruction on Student Learning Outcomes

Table 6. Regression Model for Technology and Student Learning Outcomes

Regression Model for Technology and Student Learning Outcomes

\begin{tabular}{|c|c|c|c|c|c|c|c|c|c|c|}
\hline $\begin{array}{l}\text { Independent } \\
\text { Variables }\end{array}$ & \multicolumn{2}{|c|}{$\begin{array}{l}\text { General Education } \\
\text { Gains }(N=1768)\end{array}$} & \multicolumn{2}{|c|}{$\begin{array}{l}\text { Personal and Social } \\
\text { Development Gains } \\
\qquad(N=1768)\end{array}$} & \multicolumn{2}{|c|}{$\begin{array}{l}\text { Intellectual Gains } \\
\qquad(N=1779)\end{array}$} & \multicolumn{2}{|c|}{$\begin{array}{c}\text { Science and } \\
\text { Technology Gains } \\
(N=1790)\end{array}$} & \multicolumn{2}{|c|}{$\begin{array}{l}\text { Vocational Gains } \\
\qquad(N=1791)\end{array}$} \\
\hline Gender & -.01 & -.001 & $.09 * *$ & $.07 * *$ & .14 & .01 & $-.24 * * *$ & $-.14 * * *$ & -.03 & -.02 \\
\hline Race & -.19 & -.02 & -.03 & -.02 & -.07 & -.05 & -.12 & -.06 & -.04 & -.02 \\
\hline $\begin{array}{l}\mathrm{R}^{2} \text { Background } \\
\text { Variables }\end{array}$ & & .03 & & $.02 * * *$ & & $.02 * * *$ & & $.02 * * *$ & & $.08 * *$ \\
\hline Gender & -.22 & -.02 & .05 & .04 & -.02 & -.02 & $-.25 * * *$ & $-.15 * * *$ & -.06 & -.04 \\
\hline $\begin{array}{l}\text { Searched the } \\
\text { Internet for } \\
\text { course related } \\
\text { material }\end{array}$ & $.64 * * *$ & $.10^{* * *}$ & $.11 * * *$ & $.13 * * *$ & .12 & $.16^{* * * *}$ & $.14 * * *$ & $.12 * * *$ & $.10 * * *$ & $.11 * * *$ \\
\hline $\begin{array}{l}\text { Used email to } \\
\text { communicate } \\
\text { with class }\end{array}$ & .38 & .05 & $.10 * * *$ & $.09 * * *$ & .07 & .07 & .01 & .008 & -.02 & .07 \\
\hline
\end{tabular}




\section{ABOUT THE AUTHORS}

Darrell L. Cain is currently a Dean of Instruction at Atlanta Technical College in Atlanta, Georgia. He also serves as a coordinator for the Georgia Virtual Technical College at Atlanta Tech and serves as an Adjunct Assistant Professor at Argosy University for the School of Education. He earned his doctorate from Virginia Tech University in Educational Leadership and Policy Studies with a concentration in Instructional Technology.

Paul E. Pitre is a professor of Educational Leadership and Counseling Psychology at Washington State University. His academic interests include college teaching, leadership and governance, and equity in educational policy. Pitre completed his Ph.D. in Educational Policy and Leadership at the University of Maryland, College Park. 